\title{
ON I $_{2}$ - STATISTICALLY CONVERGENT AND I I $_{2}$ STATISTICALLY CAUCHY SEQUENCE OF DOUBLE SEQUENCES IN TWO NORMED SPACES OVER ULTRAMETRIC FIELDS
}

\author{
K. SUJA* \& S. SANGEETHA
}

Department of Mathematics, SRM Institute of Science and Technology, Kattankulathur-603203, Tamilnadu, India

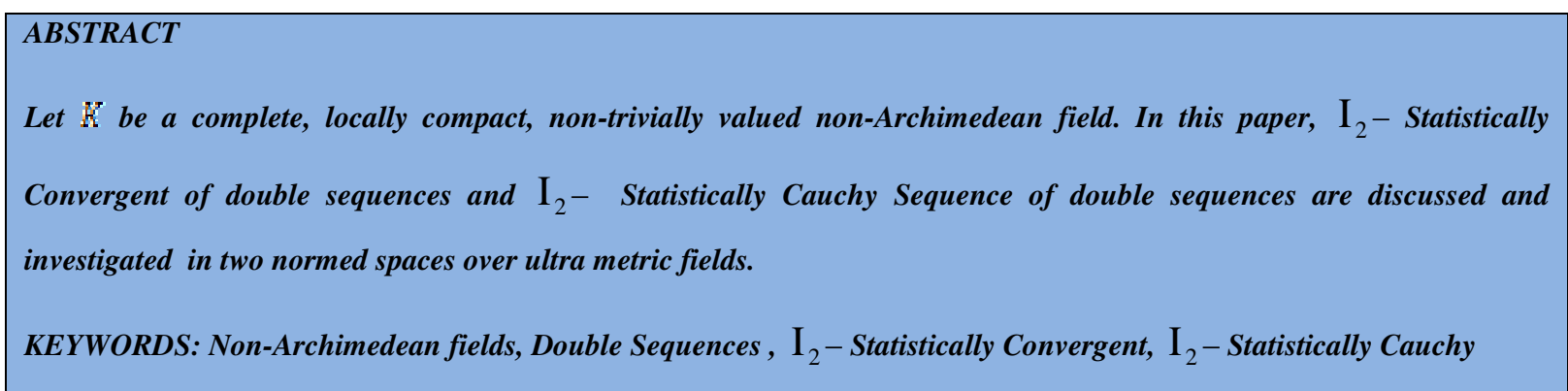

Received: Jun 09, 2020; Accepted: Jun 29, 2020; Published: Aug 05, 2020; Paper Id.: IJMPERDJUN2020637

\section{INTRODUCTION}

Fast [8] introduced the statistical convergence concept to sequences of real numbers. Several authors (see [7,14]) have investigated the concept of generalizations, applications of real numbers and the concept of ideal convergence was introduced by P.Kostyrko et.al [13]. The notion of Ideal convergence, Ideal Cauchy and I*-Cauchy double sequences in a linear metric space were studied by E. Dundar and B.As an extension many authors were discussed more concepts on ideal convergence and ideal Cauchy sequences [2.3,4,5,6,11,14,16].The generalization of statistical convergence was established as an ideal convergence by P.Kostyrko et.al [13]. S. Gahler [10] introduced the idea of 2-normed spacesin 1960's. As a classical analogue of normed spaces, this was further investigated by many mathematicians. Many researchers $[17,11,5]$ studied the ideal convergence, $I$-Cauchy sequences respectively and $I_{2}$-Cauchy for double sequence in 2-normed spaces. The concepts of ideal statistical convergence and ideal statistically Cauchy sequence for a single sequence in a 2-normed space was studied by Gurdal [20]. Now, studying the concepts of I- Statistically Convergent and I - Statistically Cauchy Sequences seems to be an important aspect. Here these two concepts are investigated over Two Normed Spaces.

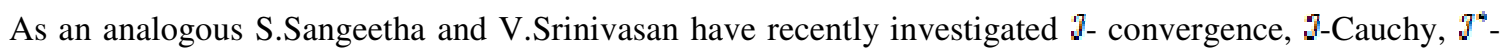
convergence and $7^{*}$-Cauchy sequences in 2-normed spaces $\mathrm{X}$ over non-Archimedean field $\mathrm{K}$ and they studied some basic properties of these concepts and relation between them in non-Archimedean normed spaces X over K [19].

In this paper, we will discuss the idea $\mathrm{I}_{2}$ - Statistically convergent of double sequences, $\mathrm{I}_{2}$ - Statistically Cauchy sequence of double sequences in non-Archimedean two normed spaces over non-Archimedean field $\mathrm{K}$ and we are going to prove some basic properties of these concepts and relation between them in non-Archimedean two normed spaces over K. 
Let us consider all through $\mathrm{K}$ denotes a complete, locally compact, non-trivially valued, non-archimedean field. For non-archimedean fields one can refer [1], and any general reference of classical analysis can be found [8].

A non-empty subset $\mathrm{I}$ of a ring $\mathrm{R}$ of subsets of $\mathbb{N} \subset \mathrm{X}$ is an ideal in $\mathrm{R}$ if and only if

(i) $A, B \in I$ implies $A \cup B \in I$.

\section{(1i) $A \in I, B \in \mathbb{R}, B \subset A$ implies $B \in \mathbb{I}$.}

An ideal is called non-trivial if $\mathbb{I} \neq \varnothing$ and $\mathbb{N} \notin \mathbb{I}$, while a non-trivial ideal $\mathrm{I}$ in $\mathbb{N}$ is said to be an admissible if $\{x\} \in \mathbb{I}$ for any $x \in \mathbb{N}$, where $\mathbb{N}$ denotes the set of positive integers.

Given a non-trivial ideal $\mathrm{I}$, the sequence $\left(x_{m}\right), x_{m} \in \mathbb{K}$, is said to be $\mathbb{I}$-convergent to $\ell \in \mathbb{K}$ if for every $\varepsilon>0$ the set $\left\{m \in \mathbb{N}:\left\|x_{m}-\ell\right\| \geq z \in \mathbb{1}\right.$.In this case, we write,

$$
\mathbb{I}-\lim _{\mathrm{m} \rightarrow \infty} x_{\mathrm{m}}=\ell
$$

For an admissible ideal land $\mathrm{X}$ being a non-archimedean normed space, the sequence $\left(x_{\mathrm{m}}\right), x_{\mathrm{m}} \in \mathrm{X}$ is called $\mathrm{I}$-Cauchy sequence in $\mathrm{X}$ if for all $\boldsymbol{s}>0$,

$\left.f m \in \mathbb{N}:\left\|x_{m+1}-x_{m}\right\| \geq z\right\} \in \mathbb{I}$.

\section{I $_{2}$-STATISTICAL CONVERGENCE IN TWO NORMED SPACES}

\section{Definition 2.1}

Let $\mathrm{X}$ be a non-archimedean vector space with dimension $\mathrm{d}$, where $2 \leq \mathrm{d}<\infty$. The Two norm on $\mathrm{X}$ is a function

II. . . II: $X x X \rightarrow K$ Which satisfies

- $\|x, y\|=0$ iff $x$ and $y$ are linearly independent,

- $\|x, y\|=\|y, x\|$

- $\|\alpha x, y\|=\|\alpha\|\|x, y\|, a \in K$

- $\|x, y+z\| \leq \max \{\|x, y\|,\|x, z\|\}$

And the pair $(X,\|. .\|$.$) denotes a two normed space.$

\section{Definition 2.2}

The sequence $\left\{x_{\mathrm{m}}\right\}$ of $\mathrm{X}$ is said to bel- statistically convergent to $l$ in two normed space for a non-trivial ideal $\mathrm{I}$, if for any $\varepsilon>0$ and $u \overline{i n} X$ the set

$$
\left.\lim -\mid m \in N i m \leq n,\left\|x_{u}-Z, u\right\| \geq \varepsilon\right\} \in I \mid=0
$$

If $\left\{x_{m}\right]$ is $]$ - statistically convergent to $l$ in two normed space. Let us denote

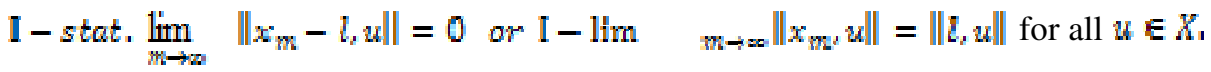


Here $l$ is the $\mathbf{I}$ - statistical limit of the sequence $\left\{x_{m}\right\}$.

\section{Definition 2.3}

The sequence $\left\{x_{m}\right\}$ of $\mathrm{X}$ is said to bel-statistically Cauchy sequence in two normed space, if for every $\varepsilon>0$ and $u$ in $X$ the set

$$
\left.\lim \frac{1}{-}|n \in N: m \leq n:| x_{-,},-x_{m}, u \| \geq \varepsilon\right\} \in I \mid=0
$$

If $\left[x_{m}\right]$ is 1 -statistically cauchy sequence in two normed space then we can write

I- stat. $\lim _{\mathrm{m} \rightarrow \mathrm{i}}\left\|x_{\mathrm{m}+1}-x_{\mathrm{m}}, u\right\|=0$, for all $u \in X$.

\section{Definition 2.4}

Let $K$ be a complete, non-trivially valued non-archimedean field. A double sequence $\left\{x_{i j}\right\}, x_{i j} \in K$ is said to be $\mathrm{I}_{2}$-statistically convergent to a limit ' $\boldsymbol{E}$ ' in two normed space for non-trivial ideal $\mathrm{I}_{2}$, if for any $z>0$ and $u \boldsymbol{m} X$ the set

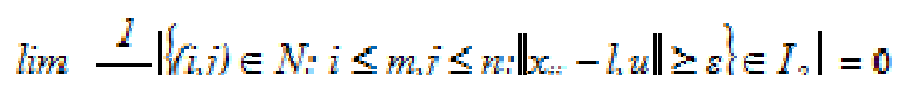

Symbolically, we write $\mathrm{I}_{2}$-stat. $\lim _{\mathrm{m} \rightarrow \mathrm{n} \rightarrow \mathrm{s}}\left\|x_{m, n}-l, u\right\|=0$, for all $u \in X$

\section{Definition 2.5}

Let $K$ be a complete, non-trivially valued non-archimedean field. A double sequence $\left\{x_{i j}\right\}, x_{i j} \in K$ is called as $\mathrm{I}_{2}-$ statistically Cauchy double sequence in two normed space for non-trivial ideal $\mathrm{I}_{2}$, if for any $z>0$ and $u \min X$, the set

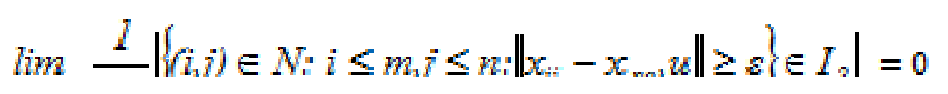

\section{Theorem 2.6}

Let $\left\{x_{\mathrm{mm}}\right]$ be the double sequence for each $u \in X, \mathrm{I}_{2}-$ stat. lim

$$
m+11 \rightarrow+\infty\left\|x_{m n}, u\right\|=\left\|l_{1}, u\right\|
$$

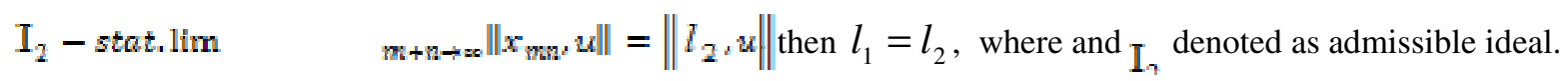

\section{Proof}

For any $u \in X$, let us assume that,

$$
\begin{aligned}
& A_{1}(\varepsilon, u)=\lim _{m+n \rightarrow \infty} \frac{1}{m n}\left|\left\{(i, j) \in N: i \leq m, j \leq n:\left\|x_{i j}-l_{1}, u\right\| \geq \varepsilon\right\} \in I_{2}\right|=0 \\
& A_{2}(\varepsilon, u)=\lim _{m+n \rightarrow \infty} \frac{1}{m n}\left|\left\{(i, j) \in N: i \leq m, j \leq n:\left\|x_{i j}-l_{2}, u\right\| \geq \varepsilon\right\} \in I_{2}\right|=0
\end{aligned}
$$


Consider,

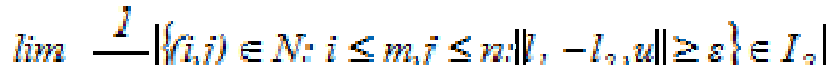

$$
\begin{aligned}
& =\lim _{m+n \rightarrow \infty} \frac{1}{m n}\left|\left\{(i, j) \in N: i \leq m, j \leq n:\left\|l_{1}-x_{i j}+x_{i j}-l_{2}, u\right\| \geq \varepsilon\right\} \in I_{2}\right| \\
& =\lim _{m+n \rightarrow \infty} \frac{1}{m n}\left|\left\{(i, j) \in N: i \leq m, j \leq n:\left\|\left(l_{1}-x_{i j}\right)+\left(x_{i j}-l_{2}\right), u\right\| \geq \varepsilon\right\} \in I_{2}\right| \\
& \leq \max \left\{\lim _{m+n \rightarrow \infty} \frac{1}{m n}\left|\left\{(i, j) \in \mathrm{N}: i \leq m, j \leq n:\left\|x_{i j}-l_{1}, u\right\| \geq \varepsilon\right\} \in \mathrm{I}_{2}\right|\right. \\
& \left.\lim _{m+n \rightarrow \infty} \frac{1}{m n}\left|\left\{(i, j) \in \mathrm{N}: i \leq m, j \leq n:\left\|x_{i j}-l_{2}, u\right\| \geq \varepsilon\right\} \in \mathrm{I}_{2}\right|\right\} \\
& \rightarrow 0, \text { as } n \rightarrow \infty
\end{aligned}
$$

Hence, $l_{1}=l_{2}$.

\section{Theorem 2.7}

If $I$ is an admissible Ideal and if $\mathrm{I}_{2}-$ stat.lim $\mathrm{m}+\mathrm{n} \rightarrow \mathrm{x}\left\|x_{\mathrm{m}}, u\right\|=\left\|l_{1}, u\right\| \quad$ and $\mathrm{I}_{2}-$ stat.lim $m+n+z=\left\|y_{m,}, u\right\|=\left\|l_{2}, u\right\| \quad$ then,

- $\mathbf{I}_{2}-$ stat.lim $m+n+z=x_{m}+y_{m}, u\|=\| l_{1}+l_{2}, u \| ;$

- $\mathrm{I}_{2}-$ stat.lim $m+n \rightarrow \infty x\left\|c x_{m}, u\right\|=\|\alpha d, u\|$ for every $u \in X$ and $\alpha \in K$.

\section{Proof}

- Let $l_{1}$ and $l_{2}$ be the $\mathrm{I}_{2}$-statistical $\operatorname{lm}$ t of the sequence $\left[x_{m m}\right]$ and $\left\{y_{m m}\right]$ respectively.

For all $\boldsymbol{\varepsilon} \geq 0$ and $\boldsymbol{u}$ in $X$ the set $A_{1}, A_{2} \in \mathrm{I}_{2}$, where

$$
\begin{aligned}
& A_{1}(\varepsilon, u)=\lim _{m+n \rightarrow \infty} \frac{1}{m n}\left|\left\{(i, j) \in N: i \leq m, j \leq n:\left\|x_{i j}-l_{1}, u\right\| \geq \varepsilon\right\} \in I_{2}\right|=0 \\
& A_{2}(\varepsilon, u)=\lim _{m+n \rightarrow \infty} \frac{1}{m n}\left|\left\{(i, j) \in N: i \leq m, j \leq n:\left\|y_{i j}-l_{2}, u\right\| \geq \varepsilon\right\} \in I_{2}\right|=0(4)
\end{aligned}
$$

Consider,

$$
\lim _{m+n \rightarrow \infty} \frac{1}{m n}\left|\left\{(i, j) \in N: i \leq m, j \leq n:\left\|\left(x_{i j}+y_{i j}\right)-\left(l_{1}+l_{2}\right), u\right\| \geq \varepsilon\right\} \in I_{2}\right|
$$




$$
\begin{aligned}
& =\lim _{m+n \rightarrow \infty} \frac{1}{m n}\left|\left\{(i, j) \in N: i \leq m, j \leq n:\left\|\left(x_{i j}-l_{1}\right)+\left(y_{i j}-l_{2}\right), u\right\| \geq \varepsilon\right\} \in I_{2}\right| \\
& \leq \max \left\{\lim _{m+n \rightarrow \infty} \frac{1}{m n}\left|\left\{(i, j) \in N: i \leq m, j \leq n:\left\|x_{i j}-l_{1}, u\right\| \geq \varepsilon\right\} \in I_{2}\right|,\right. \\
& \left.\lim _{m+n \rightarrow \infty} \frac{1}{m n}\left|\left\{(i, j) \in N: i \leq m, j \leq n:\left\|y_{i j}-l_{2}, u\right\| \geq \varepsilon\right\} \in I_{2}\right|\right\} \\
& =0,
\end{aligned}
$$

Hence,

$$
\mathrm{I}_{2}-\text { stat.lim } \quad \quad m+n \rightarrow=x\left\|x_{\mathrm{mm}}+y_{\mathrm{mm}}, u\right\|=\left\|l_{1}+I_{2}, u\right\|
$$

- Let $\mathrm{I}_{2}-$ stat. $\lim \quad \quad \mathrm{m}+n \rightarrow-\mathrm{m}\left\|x_{\mathrm{m} m}, u\right\|=\left\|l_{1}, u\right\|$

For $\alpha \in K$ and $\alpha \neq 0$, we have

$$
\lim _{m+n \rightarrow \infty} \frac{1}{m n}\left|\left\{(i, j) \in N: i \leq m, j \leq n:\left\|x_{i j}-l_{1}, u\right\| \geq \frac{\varepsilon}{|\alpha|}\right\} \in I_{2}\right|=0 \text { (5) }
$$

Now, we shall prove that,

$$
\mathrm{I}_{2}-\text { stat. } \lim \left\|\alpha x_{m n}, u\right\|=\|\alpha L, u\| \text { for every } u \in X \text { and } \alpha \in K \text {. }
$$

That is, to prove $\mathrm{I}_{2}-$ stat. lim

$$
m+n \rightarrow m\left\|\alpha x_{m}-\alpha h_{1}, u\right\|=0
$$

It is given that,

$$
\begin{aligned}
& \lim _{m+n \rightarrow \infty} \frac{1}{m n}\left|\left\{(i, j) \in N: i \leq m, j \leq n:\left\|\alpha x_{i j}-\alpha l_{1}, u\right\| \geq \varepsilon\right\} \in I_{2}\right| \\
& \quad=\lim _{m+n \rightarrow \infty} \frac{1}{m n}\left|\left\{(i, j) \in N: i \leq m, j \leq n:\left\|\alpha\left(x_{i j}-l_{1}\right), u\right\| \geq \varepsilon\right\} \in I_{2}\right| \\
& \quad=\lim _{m+n \rightarrow \infty} \frac{1}{m n}\left|\left\{(i, j) \in N: i \leq m, j \leq n:\left|\alpha\left\|\mid\left(x_{i j}-l_{1}\right), u\right\| \geq \varepsilon\right\} \in I_{2} \mid\right.\right. \\
& =\lim _{m+n \rightarrow \infty} \frac{1}{m n}\left|\left\{(i, j) \in N: i \leq m, j \leq n:\left\|x_{i j}-l_{1}, u\right\| \geq \frac{\varepsilon}{|\alpha|}\right\} \in I_{2}\right|
\end{aligned}
$$

Therefore, $\mathrm{I}_{2}-$ stat. lim

$$
\left\|a x_{\operatorname{man}}-a l_{1}, u\right\|=0, \text { for every } u \in X .
$$

Hence the proof is complete. 
Let us prove the theorem by considering a basis $v=\left\{v_{1}, v_{2}, v_{2}, \ldots, v_{d}\right\}$ for $\mathrm{X}$.

\section{Theorem 2.8}

If $\mathrm{I}_{\text {n }}$ is an admissible ideal then the double sequence $\left[x_{m}\right]$ in $X$ is $I_{n}$ - statistically convergent to $\operatorname{Iin} X$ if and only if $\mathrm{I}_{2}-$ stat.lim $\quad\left\|x_{\mathrm{m}}-l, v_{i}\right\|=0$

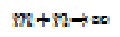

For every $i=1,2, \ldots, d$.

\section{Proof}

Let us assume that the double sequence $\left\{x_{\mathrm{m}}\right]$ in $\mathrm{X}$ is $\mathrm{I}_{2}$ - statistically convergent to $l$ in $\mathrm{X}$.

That is,

$I_{2}-s t a t . \lim \quad \quad m+n \rightarrow m\left\|x_{m n}-l, z\right\|=0(6)$

Where $z=\alpha_{1} v_{1}+\alpha_{2} v_{2}+\ldots+\alpha_{d} v_{d}, \alpha_{1}, \alpha_{2}, \ldots \alpha_{d} \in K$

To prove

$$
\mathrm{I}_{2}-\operatorname{stat} . \lim _{m+m \rightarrow \infty}\left\|x_{m \mathrm{~m}}-l, v_{i}\right\|=0
$$

Consider

$$
\begin{aligned}
& \lim _{m+n \rightarrow \infty} \frac{1}{m n}\left|\left\{(i, j) \in N: i \leq m, j \leq n:\left\|x_{i j}-l, z\right\| \geq \varepsilon\right\} \in I_{2}\right| \\
& =\lim _{m+n \rightarrow \infty} \frac{1}{m n}\left|\left\{(i, j) \in N: i \leq m, j \leq n:\left\|x_{i j}-l, \alpha_{1} v_{1}+\alpha_{2} v_{2}+\ldots+\alpha_{d} v_{d}\right\| \geq \varepsilon\right\} \in I_{2}\right| \\
& \leq \max _{m+n \rightarrow \infty} \frac{1}{m n}\left|\left\{(i, j) \in N: i \leq m, j \leq n:\left\|x_{i j}-l, \alpha_{1} v_{1}\right\|,\left\|x_{i j}-l, \alpha_{2} v_{2}\right\| . . . \mid x_{i j}-l, \alpha_{d} v_{d} \| \geq \varepsilon\right\} \in I_{2}\right| \\
& \leq \max _{1 \leq i \leq d}\left\{\operatorname { l i m } _ { m + n \rightarrow \infty } \frac { 1 } { m n } \left|\left\{(i, j) \in N: i \leq m, j \leq n:\left|\alpha\left\||| x_{i j}-l, v_{i}\right\| \geq \varepsilon\right\} \in \mathrm{I}_{2} \mid\right\}\right.\right.
\end{aligned}
$$

Since

$$
\begin{aligned}
& \mathrm{I}_{2}-\text { gtat.lim }\left\|x_{m m}-l, z\right\|=0 \\
& I_{2}-s t a t . \lim \mid m+n \rightarrow \infty=1,2, \ldots d .
\end{aligned}
$$

Conversely, we now assume that if $I_{2}-$ stat. $\lim \quad m_{n \rightarrow \infty}\left\|x_{m n}-\Sigma_{n} v_{i}\right\|=0$, for every $i=1,2, \ldots, d$. 

Normed Spaces over Ultrametric Fields

Let us now prove that

$$
\mathrm{I}_{2}-\operatorname{stat.} \lim _{\mathrm{m} \rightarrow \mathrm{m} \rightarrow \infty}\left\|x_{\mathrm{mm}}-l, z\right\|=0
$$

For all non-zero $z \in X$.

$$
\begin{aligned}
& \lim _{m+n \rightarrow \infty} \frac{1}{m n}\left\{(i, j) \in N: i \leq m, j \leq n:\left\|x_{i j}-l, z\right\| \geq \varepsilon\right\} \in I_{2} \mid \\
& =\lim _{m+n \rightarrow \infty} \frac{1}{m n}\left|\left\{(i, j) \in N: i \leq m, j \leq n:\left\|x_{i j}-l, \alpha_{1} v_{1}+\alpha_{2} v_{2}+\ldots+\alpha_{d} v_{d}\right\| \geq \varepsilon\right\} \in I_{2}\right| \\
& \leq \max _{m+n \rightarrow \infty} \frac{1}{m n}\left|\left\{(i, j) \in N: i \leq m, j \leq n:\left\|x_{i j}-l, \alpha_{1} v_{1}\right\|, \cdot\left\|x_{i j}-l, \alpha_{2} v_{2}\right\| \ldots .\left\|x_{i j}-l, \alpha_{d} v_{d}\right\| \geq \varepsilon\right\} \in I_{2}\right| \\
& \leq \max _{1 \leq i \leq d}\left\{\lim _{m+n \rightarrow \infty} \frac{1}{m n}\left|\left\{(i, j) \in N: i \leq m, j \leq n:|\alpha|\left\|x_{i j}-l, v_{i}\right\| \geq \varepsilon\right\} \in \mathrm{I}_{2}\right|\right\} \\
& \leq \max _{1 \leq i \leq d}\left\{\lim _{m+n \rightarrow \infty} \frac{1}{m n}\left\{\left\{(i, j) \in N: i \leq m, j \leq n:\left\|x_{i j}-l, v_{i}\right\| \geq \frac{\varepsilon}{\left|\alpha_{i}\right|}\right\} \in \mathrm{I}_{2} \mid\right\}\right.
\end{aligned}
$$

Since, $\mathrm{I}_{2}-$ stat.lim $\left\|x_{\min }-l v_{\mathrm{i}}\right\|=0$,

We have $\lim _{m+n \rightarrow \infty} \frac{1}{m n}\left|\left\{(i, j) \in N: i \leq m, j \leq n:\left\|x_{i j}-l, v_{i} \mid\right\| \geq \varepsilon\right\} \in I_{2}\right|=0$, for every $\varepsilon>0$.

Therefore,

$$
\Rightarrow \quad \mathrm{I}_{2}-\text { stat. } \lim \left\|x_{\min }-l_{z} z\right\|=0
$$

Hence the theorem

We now define a norm on $\mathrm{X}$ with respect to the basis $v=\left\{v_{1}, v_{2}, v_{3}, \ldots, v_{d}\right\}$ and is denoted by

$$
\|x\|_{\infty \infty}=\max \left[\left\|x, v_{i}\right\|: i=1,2, \ldots, d\right]
$$

\section{Theorem 2.9}

If $\mathrm{I}_{2}$ is an admissible ideal then the double sequence $\left\{x_{\operatorname{man}}\right\}$ in X is $\mathrm{I}_{2}$-statistically convergent to $l$ in $\mathrm{X}$ if and only

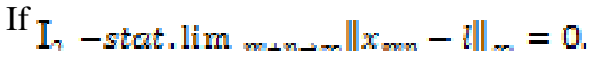

\section{Theorem 2.10}

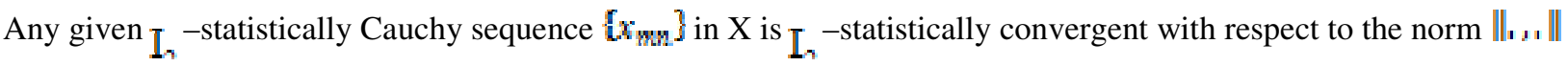


If and only if it is $\mathbf{I}_{7}-$ statistically convergent with respect to the norm $\left\|_{2 . .}\right\|_{z e}$ where

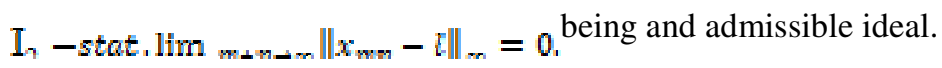

\section{Proof}

From Theorem 3 and 4, we have,

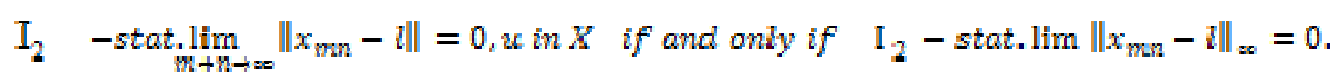

Also we have,

$\left[x_{m}\right]_{\text {is }}$ an Ideal statistically Cauchy double sequence with respect to $\|.,$.$\| if and only if$

$$
\begin{aligned}
& \mathrm{I}_{2}-\text { stat. } \lim _{\mathrm{m}+\mathrm{n} \rightarrow \mathrm{x}}\left\|x_{\min }-x_{\mathrm{pq}}, v\right\|=0 \text { For all } v \text { in } \mathrm{X} \\
& \Leftrightarrow \mathrm{I}_{2}-\operatorname{stat} . \lim _{\mathrm{m} \rightarrow \infty}\left\|x_{\mathrm{m}}-x_{\mathrm{g} q^{2}} v_{i}\right\|=0, \bar{i}=1,2, \ldots, d,
\end{aligned}
$$

Where $v$ is the basis

$$
\Leftrightarrow \mathrm{I}_{2}-\underset{\mathrm{m} \rightarrow \mathrm{stat}}{\lim \|}\left\|x_{\mathrm{ma}}-x_{\mathrm{pq}}, v_{\mathrm{i}}\right\|_{\mathrm{m}}=0
$$

Therefore, $\left\{x_{\mathrm{mm}}\right\}$ is an $\mathrm{I}_{2}$-statistically Cauchy sequence with respect to $\|.\|_{z}$

Hence the theorem is proved.

\section{REFERENCES}

1. G. Bachman, Introduction to p-adic numbers and valuation theory, Academic Press, 1964.

2. P. Das, P. Kostyrko, W. Wilczyncki, P. Malik, “I and I* Convergence of double sequences”, it Math Slovaca, Vol 58, No.5,2008,pp.605-620

3. P. Das, P. Malik, “On extremal I-limit points of double sequences”,Tatra Mt. Math, 40, 2008, pp. 91-102.

4. K. Demirci, “I-limit superior and I-limit inferior", Math. Commun., 6, 2001,pp. 165-172.

5. E. Dundar, B. Altay, On some properties of I2-convergence and I2-Cauchy of double sequences, Gen. Math. Notes, 7(1) (2011), 1-12.

6. E. Dundar, B. Altay, I2-convergence and I2-Cauchy of double sequences, Acta Mathematica Scientia, 34B(2) (2014), 343353.

7. Wagh, Mamta Amol, and Sanjeev Kumar. "Köthe Töeplitz Duals of Certain Bicomplex Sequence Spaces." Inter. J. Math. \& Comp. App. Research (IJMCAR) 4.3 (2014).

8. M. Eshaghi Gorgy, F. AmoueiArani, S. "Statistical convergence of double sequences in paranormed spaces", JMCS, 2014, 47-53.

9. H. Fast, "Sur la Convergence statistique", Colloq. Math. 2, 1951, 241-244.

10. J. A. Fridy, "On Statistical Convergence”, Analysis, 5, 1985, pp. 301-313. 
11. Raad, S A, and M M Alatawi. "A Numerical Treatment of Two-Dimensional Quadratic Volterra Integral Equation of the Second Kind."International Journal of Mathematics and Computer Applications Research (IJMCAR) 9. 2, Dec 2019, 53-62

12. S.Gahler, "2- metrischeRaume und ihretopolpgischeStruktur”, Math. Nachr., 26, 1963, pp. 115-148.

13. M. Gurdal, I.Acik, “On I-Cauchy Sequences in 2-normed spaces, Math. Inequal. Appl.,11, no.2, 2008 ,pp 349-354

14. G.H. Hardy, Divergent Series, Oxford, 1949.

15. Powar, P. L., and G. R. K. Sahu. "Serendipity fixed point." International Journal of Mathematics and Computer Applications Research (IJMCAR) ISSN (2013): 2249-6955.

16. P. Kostyrko, T. Salat, W. Wilczynski, “I-Convergence”, Real Analysis Ex-change.,26(2), 2001, pp. 669-686.

17. Mursaleen, Osama, H. H. Edely, Statistical convergence of double sequences, J. Math. Anal. Appl., 288, 2003, $223-231$.

18. A. Nabiev, S. Pehlivan, M. Gurdal, “On I-cauchy sequences”, Taiwanese Journal of Mathematics, 11(2), 2007, pp. 569-576.

19. S.Sarabadan, S.Talebi, Statistical convergence and Ideal convergence of sequences of functions in 2-normed spaces, Inter. J. Math. Math. Sci.,(2011), 10 pages.

20. Abed, Salwa Salman, and Rana Fadhil Abbas. "S-iteration for general quasi multi valued contraction mappings." Int. J. Appl. Math. Stat. Sci, 5 (4), 922 (2016).

21. S. Saraban, F.A. Arani, S. Khalehoghli, "A condition for the equivalence of I and I* convergence in 2-normed spaces, Int.J. Comtemp. Math. Sci, 43,no.6, 2011, pp.2147-2156.

22. A.Sahine, M. Gurdal, S.Saltan and H. Gunawan, “Ideal convergence in 2-normed spaces”, Taiwanese Journal of Mathematics, 11(5), 2007, pp.1477-1484.

23. S. Sangeetha, V.Srinivasan, "I-Cauchy sequence and I-core of a sequence in Ultrametric Fields", Int. J. of Pure and Applied Mathematics, 113(10), 2017, pp.17-19.

24. K. Suja and V. Srinivasan, "On Statistically Convergent and Statistically Cauchy Sequences in Non-Archimedean Fields", Journal of Advances in Mathematics, 6(3), 2014, 1038-1043.

25. U. Yamanc and M. Gurdal, “I-Statistical convergence in 2-normed spaces”, Arab Journal of Mathematical Sciences, 20(1), 2014, pp. 41-47. 

